\title{
The impact of providing rapid diagnostic malaria tests on fever management in the private retail sector in Ghana: a cluster randomized trial
}

\author{
(c) (1) (8) OPEN ACCESS
}

\author{
Evelyn K Ansah deputy director ${ }^{1}$, Solomon Narh-Bana field epidemiologist ${ }^{2}$, Harriet Affran-Bonful \\ pharmacist $^{3}$, Constance Bart-Plange programme manager ${ }^{4}$, Bonnie Cundill lecturer in statistics ${ }^{5}$, \\ Margaret Gyapong director ${ }^{2}$, Christopher $\mathrm{J} \mathrm{M}$ Whitty professor of public and international health ${ }^{5}$
}

${ }^{1}$ Research and Development Division, Ghana Health Service, PO Box MB-190, Accra, Ghana; ${ }^{2}$ Dodowa Health Research Center, Ghana Health Service; ${ }^{3}$ Dangme West District Health Directorate, Ghana Health Service; ${ }^{4}$ National Malaria Control Programme, Ghana Health Service; ${ }^{5}$ London School of Hygiene \& Tropical Medicine, London, UK

\begin{abstract}
Objective To examine the impact of providing rapid diagnostic tests for malaria on fever management in private drug retail shops where most poor rural people with fever present, with the aim of reducing current massive overdiagnosis and overtreatment of malaria.

Design Cluster randomized trial of 24 clusters of shops.

Setting Dangme West, a poor rural district of Ghana.

Participants Shops and their clients, both adults and children.

Interventions Providing rapid diagnostic tests with realistic training.

Main outcome measures The primary outcome was the proportion of clients testing negative for malaria by a double-read research blood slide who received an artemisinin combination therapy or other antimalarial. Secondary outcomes were use of antibiotics and antipyretics, and safety.

Results Of 4603 clients, 3424 (74.4\%) tested negative by double-read research slides. The proportion of slide-negative clients who received any antimalarial was 590/1854 (32\%) in the intervention arm and $1378 / 1570(88 \%)$ in the control arm (adjusted risk ratio $0.41(95 \% \mathrm{Cl}$ 0.29 to 0.58$), P<0.0001)$. Treatment was in high agreement with rapid diagnostic test result. Of those who were slide-positive, 690/787 (87.8\%) in the intervention arm and $347 / 392(88.5 \%)$ in the control arm received an artemisinin combination therapy (adjusted risk ratio 0.96 (0.84 to 1.09)). There was no evidence of antibiotics being substituted for antimalarials. Overall, 1954/2641 (74\%) clients in the intervention arm and 539/1962 (27\%) in the control arm received appropriate treatment (adjusted risk ratio 2.39 (1.69 to 3.39 ), $\mathrm{P}<0.0001$ ). No safety concerns were identified.

Conclusions Most patients with fever in Africa present to the private sector. In this trial, providing rapid diagnostic tests for malaria in the private drug retail sector significantly reduced dispensing of antimalarials to patients without malaria, did not reduce prescribing of antimalarials
\end{abstract}

to true malaria cases, and appeared safe. Rapid diagnostic tests should be considered for the informal private drug retail sector.

Registration Clinicaltrials.gov NCT01907672

\section{Introduction}

Malaria remains one of the most common diagnoses in Africa, and fever the commonest outpatient presentation, although most children and adults with fever present solely to the private drug retail sector (shops) rather than formal health services. A serious problem of over-prescription of antimalarials to patients without malaria has been found across the continent. ${ }^{12}$ There has been a major shift in emphasis on treatment of febrile illness in the formal health sector in Africa that antimalarial treatment should always be guided by parasitological testing. ${ }^{34}$ This has been driven by several factors, including that a large proportion of patients with fever are being given antimalarials when they have other, potentially serious causes of infection which are being missed, ${ }^{1.7}$ the waste of relatively expensive antimalarials on patients without malaria, and that unnecessary antimicrobial use helps drive drug resistance and exposes patients to unnecessary side effects. ${ }^{2}$ As a result of these efforts, overdiagnosis of malaria in the public sector is now falling rapidly.

However, most children and adults with febrile illness, including the poorest, are treated in the private drug retail sector in most countries in Africa, including Ghana, even where public sector treatment is free ${ }^{8-16}$ Strengthening the use of diagnostic tests for malaria in public health facilities therefore affects only a minority of cases of over-prescription of antimalarials. In rural areas in particular, most of the poorest often access antimalarials through the private drug retail sector, largely because of the transport cost and opportunity cost (things people could 
otherwise spend money on) of accessing healthcare. ${ }^{17-20}$ In recognition of this, several schemes, including the Affordable Medicines Facility for malaria have been deployed to ensure that effective antimalarials are available through private outlets that poorer patients use. ${ }^{21} 22$ These schemes have provided drugs, but generally not diagnostic support, and poor targeting of antimalarials is recognized as a major risk to these efforts. ${ }^{23}$ Reducing overtreatment of malaria in the private sector is becoming increasingly important as the proportion of fevers attributable to malaria reduces so the relative importance of non-malaria causes increases. ${ }^{24} 25$

Rapid diagnostic tests for malaria are potentially usable in peripheral private drug retail facilities. They are sensitive and can be used with minimal training. ${ }^{26}$ In the formal public sector, substituting these for clinical (non-test based) diagnosis in peripheral settings without access to laboratories generally leads to significantly better targeting of antimalarials and less over-prescription, including in Ghana, provided it is linked to training. ${ }^{20-31}$ For this reason, providing free or subsidized rapid diagnostic tests has been strongly advocated by some to be provided for use in the private drug retail sector including, in the UK, the Public Accounts Committee of the House of Commons and National Audit Office, ${ }^{16}$ but without a strong evidence base that they can be used correctly. The scale of subsidy this would require is substantial; it is estimated there are 656 million fevers a year in African children aged 0-4 years old alone, of which only a minority go to the public sector. ${ }^{25}$ It would change the nature of healthcare provision in Africa, making private providers diagnosticians, until now the preserve of clinicians. The evidence base to support this significant policy change is weak with little reliable data from Africa outside observational studies, and some less encouraging data from the very different setting of South East Asia. ${ }^{30} 32$

There are several reasons why a technology that works in the formal public sector may not work for shops. The most obvious is that, if they are used correctly, a major effect of rapid diagnostic tests is likely to be to reduce over-prescription of antimalarials, so the effect in the private drug retail sector could be to reduce sales of a major item, for which there may be no rational economic advantage to the seller. Conversely, incorrectly used rapid diagnostic tests in untrained hands could lead to true cases of malaria, a potentially fatal disease, not being treated because of false negative readings. There are also safety concerns around bloodborne viruses (hepatitis, HIV, Ebola); sharps disposal is difficult and sharps reuse may have some economic advantage to shopkeepers (risking clients). Additionally, sharps risk to shopkeepers is non-trivial in a setting where hepatitis B prevalence is often over $10 \%$ in blood donors. ${ }^{334}$ Private sector providers have training, incentives, backgrounds, and population served that are different from the formal public sector, so extrapolating directly from public sector data to the private sector is unwise.

This study set out to examine the impact of providing rapid diagnostic tests on antimalarial and other prescribing in the most commonly used part of the private drug retail sector in rural and semi-rural Ghana, chemical shops. In particular, we

hypothesized that providing rapid diagnostic tests will reduce overprescribing of antimalarials to clients with no malaria. We also aimed to look at safety, both in terms of deaths or adverse illness from missed malaria when rapid diagnostic tests are introduced and the use of sharps. This is one of the first trials of diagnostics in the private drug retail sector in Africa, and specifically West Africa.

\section{Methods \\ Study site and population}

The trial was carried out in Dangme West, a rural district with widespread poverty in Ghana with an estimated population of 142633 in 2009 mid-year. The people live in scattered small communities and are mostly subsistence farmers or fishermen. Vehicular transport is unavailable in many parts of the district, making access to formal care difficult. Health services are organized around a three tier system at district level, with the district hospital as the referral level, the health centre at subdistrict level, and the Community Health and Planning and Services (CHPS) compounds, which deliver close-to-client services mostly at home, at community level. There is one district hospital, three health centres, 13 CHPS compounds, and five formal private health facilities. In addition, 56 chemical shops and six pharmacies sell pharmaceutical products (fig $1 \Downarrow$ ); Licensed Chemical Sellers are the main outlet for antimalarials in Ghana.. Earlier studies carried out in the district showed that for presumed "malaria" in the household, the first action taken is, in order of the most common: home treatment, chemical shop, health centre, hospital, drug peddler, and traditional healer. ${ }^{12-36}$ The study was conducted across both the high and low transmission seasons.

Chemical sellers in Ghana are regulated by the Pharmacy Council. To be eligible, a person must possess a minimum of secondary school level qualification, with basic knowledge in healthcare delivery being an advantage. Applicants attend pre-licensing training, and the licenses are renewed annually. The shops are legally allowed to retail over-the-counter medicines to members of the public in communities that the Pharmacy Council considers poor. The authorized medicines include analgesics and antimalarials. The only antibiotic allowed is co-trimoxazole.

\section{Trial design}

A cluster randomized trial design was used, with a cluster defined as a community with at least one chemical shop. Twenty four communities, with one to five shops per community, were eligible for inclusion in the study. The trial was evaluated among clients reporting to a participating chemical shop complaining of fever or requesting an antimalarial medicine. Clients were excluded if they were pregnant, $<6$ months old, had signs of severe disease, a prescription from a health facility, or would be in the district for less than 28 days. Assessments for eligibility were carried out by the chemical sellers, who were trained to do so. Clients with severe disease or who were pregnant were referred to the nearest health centre or the district hospital by the chemical seller.

An initial baseline study was carried out involving a census, including Global Positioning System (GPS), of all chemical shops to document the location of each shop and antimalarials available. The results of the baseline informed the study design. As part of formative research, focus group discussions were held with community members and chemical sellers to find out how acceptable the idea of chemical sellers testing for malaria in shops was, to community members and the best way to introduce the intervention.

\section{The intervention}

Shops in communities randomised to the control arm were expected to dispense medicines without test results as per current practice, while those in the intervention arm carried out a test for malaria using an rapid diagnostic test before dispensing any 
medication. In positive malaria tests, rapid diagnostic tests form a coloured line in the test area. Tests generally take 15-20 minutes depending on the test kit. CareStart Malaria HRP2 (Pf) rapid diagnostic test kits, which fulfil all the WHO assessment criteria, were provided by the study team on a monthly basis and were free of charge to chemical sellers and clients. The study team carried out regular quality control procedures by picking a random sample of test kits from the shop for testing using standard positive blood samples. This was to ensure that the rapid diagnostic test kits continued to perform optimally under the storage conditions in the chemical shop.

All chemical sellers attended a three day training on malaria, covering topics that included the antimalarial drug policy of Ghana; causes, signs, and symptoms of malaria; signs of severe disease and indications for referral; how to take a blood sample and make a blood slide; blood safety and handling of sharps; infection prevention procedures; and standard operating procedures of the study. Sellers in the intervention arm attended an additional day of training, covering how to carry out and interpret rapid diagnostic tests for malaria and further management of clients with a negative rapid diagnostic test result. The training involved a demonstration by a laboratory technologist followed by practice sessions by chemical sellers on their colleagues. They practised how to take a blood sample safely and also tested for malaria with a rapid diagnostic test. Test kits, sharps bins, and documentation were introduced and used during the training. Lecture sessions were interspersed with group discussions, role plays, and individual exercises. Assignments were marked and discussed in class. A minimum of two attendants were trained per shop to ensure continuity of service. After the training, all chemical sellers were provided with reference charts for doses of artemisinin combination therapies. Whenever a trained shop attendant resigned and was replaced by a new one, training was carried out in the shop for the new attendant.

Since Ghana was one of the phase one countries benefitting from the Affordable Medicines Facility for malaria, subsidized artemisinin combination therapy was available at the lowest level of the private drug retail sector from mid-2011, and chemical sellers were encouraged to use their regular source of supply of antimalarials. Bins for disposal of sharps and a certificate identifying the seller as a trained provider of malaria testing were also provided. Fieldworkers and supervisors were also trained separately in taking of blood samples and rapid diagnostic tests and the standard operating procedures of the study to enable them to provide technical support to the chemical sellers.

\section{Study outcomes}

The primary outcome was the proportion of clients who tested negative for malaria by a double-read research blood slide and who received an artemisinin combination therapy or other antimalarial. Secondary outcomes included treatment with antibiotics by test outcome, treatment of patients with a negative rapid diagnostic test result, treatment with other antimalarials or alternative treatments, the operational sensitivity of the rapid diagnostic tests used by chemical sellers against research slide results, the safety of use of rapid diagnostic tests at community level, and the impact on numbers of referrals to formal medical care.

The presence of malaria was assessed through a blood slide, which was prepared by health centre laboratory staff from a blood sample taken by the chemical seller as part of the consultation with the client regardless of study arm. Slides were double-read in research laboratories, and discrepant slides were re-read by a third and senior microscopist. Information on the test results obtained, medications dispensed, and whether the client was referred were documented by the seller on a form designed specifically for the study. The accuracy of the records of drugs dispensed was validated by conducting random checks of the forms and through "mystery clients."

The "mystery client" complained of symptoms for himself or his child at home and submitted to a test when it was offered, observing the procedure the chemical seller followed for later documentation using a checklist. To ensure that chemical sellers correctly conducted the rapid diagnostic tests and adhered to safety and infection control procedures, direct observation of interactions between chemical sellers and clients was carried out by the study team using a checklist on a weekly basis during the first month of evaluation and for a further week mid-way through the trial in both arms.

In both arms clients were assessed for eligibility and requested to provide written consent for participation in the study. Basic demographic details were collected from all consenting clients, and a blood sample was taken by the chemical seller for the research slide. Detailed directions to the client's home were also collected for the purposes of follow-up. Chemical sellers had access to the subsidized green leaf logo artemisinin combination therapy from the open market via the Affordable Medicines Facility for malaria. In the control arm, services were provided to clients following usual practice without test results. The chemical sellers collected a blood sample in a "microtainer" for study testing but did not do rapid diagnostic test testing. Control chemical sellers used the same client record form as the intervention arm.

In the rapid diagnostic test arm consent provided by clients included consent for rapid diagnostic testing. If the test result was positive, chemical sellers were trained to encourage clients to purchase any of the three recommended artemisinin combination therapies; amodiaquine-artesunate,

arthemeter-lumefantrine, or dihydroartemisinine-piperaquine. Clients with a negative test were recommended to be referred to a nearby health facility or a facility of their choice. Clients who refused consent for a rapid diagnostic test received presumptive treatment (current practice), and reasons for the refusal of consent were documented. Blood slide results were provided to all shops after three days; the results of the blood slide were therefore not used by the chemical seller for initial dispensing decisions. Patients who were slide-positive but who had not been given an antimalarial in the chemical shop were contacted within 24 hours and requested to return to the chemical shop for an antimalarial. Follow-up was carried out on day 28 after the visit to the shop for all research slide-positive patients to determine the clinical course and outcome of the illness and care seeking behaviour after the visit to the chemical seller.

\section{Randomization and registration}

Communities were allocated to intervention or control by a process of restricted randomisation to ensure balance in covariates expected to be important correlates of the primary outcome. ${ }^{37}{ }^{38}$ Because of the differing number of shops in each community, the balance was restricted to a difference of two in the number of chemical shops per arm, the same number of communities containing only one shop per arm, and a maximum relative difference of $20 \%$ in the average number of cases per day. Randomisation used a program written in $\mathrm{R}$ (version 2.14.2) by a statistician not otherwise involved in the study. All chemical sellers from shops assigned to each arm were invited 
to a meeting with the study team, informed about their assignment, and enrolled into their study arm. Following this, community sensitization meetings and durbars (a large community meeting usually hosted by the traditional leaders of the community during which issues important to the community are discussed and consensus reached) were carried out to explain the intervention to community members.

Those preparing and reading the blood slides were blind to the study allocation and rapid diagnostic test result.

Permission was given by the Ghana Pharmacy Council for chemical shop involvement. The trial received ethical clearance from the Ethical Review Committee of the Ghana Health Service and the ethics committee of the London School of Hygiene \& Tropical Medicine. It was registered on ClinicalTrials.gov NCT01907672 before July 2011, although, because of a technical misunderstanding, there was a delay in releasing the protocol until September after trial start. (Formal release of the protocol was after randomization but before any outcome data were collected or analyzed, and no major changes were made between the attempt to register the study and the date when registration was complete.)

\section{Statistical methods}

After sample size calculations, the aim was for 24 communities (12 per arm) to be included. Calculations were conducted to determine a trial size sufficient to detect a $25 \%$ relative reduction in the primary outcome from $60 \%$ in the control arm among adults and 50\% among children. Using methods for cluster randomised trials and assuming a coefficient of variation between clusters of $0.2,80$ adults and 114 children per community were required to detect the specified reductions with $80 \%$ power at the $5 \%$ significance level. ${ }^{39}$

Data were double entered and validated using Epidata 6.1, and analyzed using STATA version 12.0 (STATA Corporation, College Station, Texas). The effect of the intervention was analyzed using published methods suitable for cluster randomized trials with fewer than 20 clusters per arm. ${ }^{38}{ }^{39}$ The observed proportion with the primary outcome was calculated for each community (cluster). Within each arm, a weighted average of the cluster proportions was taken with weights provided by the sample size for each cluster, to give the prevalence of the primary outcome in each arm. Due to the skewness in the distribution of the cluster proportions, a log transformation was applied and the mean of the log-proportions over clusters (log of the geometric mean) was estimated in each arm. The unadjusted risk ratio was then computed from exponentiation of the $\log$ of the ratio of these geometric means. The pooled variance of the log-proportions over clusters within each arm was calculated and used to obtain $95 \%$ confidence intervals and carry out formal hypothesis testing using a $t$ test on the logarithm of the risk ratio. Adjustment for covariates was made by firstly fitting a standard logistic regression model to the individual-level data, including terms for the covariates of interest, but excluding the intervention effect. From the fitted model, the expected number of events in each cluster was computed. The ratio of the observed to expected number of events in each cluster was used to calculate cluster-specific ratio residuals. The next stage of analysis was to compare the residuals between study arms using the above methods for estimating the risk ratios and $95 \%$ confidence intervals as well as hypothesis testing with the residuals replacing cluster-level proportions. Analysis by age group and analyses of secondary outcomes were conducted using the same methods.

\section{Results}

Figure $1 \Downarrow$ shows the trial profile. The trial was conducted from August 2011 to January 2013; last recruitment was 7 December 2012. Of the 4748 clients (2719 intervention, 2029 controls) enrolled in the study, 4603 (97\%) were included in the analysis (fig 1) with 145 (44 negative rapid diagnostic test result, 34 positive rapid diagnostic test result, 67 controls) not assessable because of haemolysed or clotted blood sample for the research slide. The study was unable to achieve the planned sample size specifically for the subgroup of children because of difficulties in recruiting this age group at the chemical sellers. Communities in both arms were similar (table $1 \Downarrow$ ), although control arm sellers were more likely to have had formal training in medicine dispensing.

\section{Treatment based on research slide results}

Of 4603 clients who had research blood slide results, 1854/2641 $(70 \%)$ in the intervention arm and $1570 / 1962(80 \%)$ in the control arm had a negative slide reading (no malaria). The proportion of clients negative for malaria by blood slide who received an antimalarial (artemisinin combination therapy or other antimalarial) was significantly lower in the intervention arm $(590 / 1854,32 \%)$ than the control arm $(1378 / 1570,88 \%)$ $(\mathrm{P}<0.0001)$; the adjusted risk ratio was $0.41(95 \%$ confidence interval 0.29 to 0.58 ) (table $2 \Downarrow$ ). Similar results were observed when the analysis was conducted separately in children and adults (table 2). In both study arms, among slide-negative clients who received an antimalarial, a high proportion of the antimalarials were artemisinin combination therapy; 1285/1378 $(93 \%)$ in the control arm and 557/590 (94\%) in the intervention arm.

Rapid diagnostic tests did not lead either to a reduction or increase in true malaria cases getting an effective antimalarial. Of those who were slide-positive $690 / 787$ (88\%) in the intervention arm and 347/392 (89\%) in the control arm received an artemisinin combination therapy (adjusted risk ratio 0.96 (0.84 to 1.09$)$ ).

Overall, 737 out of 3424 (21.5\%) of all slide-negative clients received an analgesic or non-steroidal anti-inflammatory drug (NSAID) without an antimalarial or antibiotic, while 579 of them received no medicine. Among all the 1179 slide-positive clients, $23(1.9 \%)$ received analgesics while $17(1.4 \%)$ received no medicine. Among slide-negative clients, 629/1854 (33.9\%) in the intervention arm and 108/1570 (6.9\%) in the control arm received an analgesic, suggesting that shopkeepers switched appropriately from selling antimalarials to selling analgesics or antipyretics to clients with non-severe illness and a negative rapid diagnostic test result (fig $2 \Downarrow$ ).

The secondary outcome of "appropriate malaria treatment" differed between clients attending shops in communities in the rapid diagnostic test arm (74\%) compared with clients in the control arm (27\%); adlusted risk ratio 2.39 (1.69 to 3.39). This composite indicator comprised clients with a positive blood slide who received an artemisinin combination therapy and clients with a negative slide who did not receive an artemisinin combination therapy or other antimalarial. There was no evidence of a difference between the arms in the former but strong evidence of an increase in the latter (adjusted risk ratio 5.28 (2.5 to 10.77)). No clients with a positive slide result and only seven with a negative slide reading received antibiotics, which chemical sellers are not allowed to dispense in Ghana (table $2 \Downarrow$ ). 


\section{Treatment on the basis of rapid diagnostic test results}

All 2719 clients visiting shops in intervention communities were tested for malaria with rapid diagnostic tests. Of these, 1368 (50.3\%) were reported negative, and $1351(49.7 \%)$ were positive. Treatment was in good agreement with the rapid diagnostic test result, as recorded by chemical sellers. Among those who were reported negative for malaria by rapid diagnostic test, only $38(3 \%)$ received an artemisinin combination therapy or other antimalarial, while $656(48 \%)$ received an analgesic and eight $(0.6 \%)$ received an antibiotic. Overall, 570/1368 (42\%) clients with a negative rapid diagnostic test received no medicine. Among clients with a positive rapid diagnostic test, $1344 / 1351(99.5 \%)$ received an antimalarial. Only five $(0.4 \%)$ received no medicine while two $(0.2 \%)$ received an analgesic (fig $3 \Downarrow$ ).

\section{Sensitivity and specificity of rapid diagnostic tests under operational conditions}

Of the 2641 clients in the rapid diagnostic test arm who had a valid research blood slide result, 29 who tested negative by rapid diagnostic test were found to be positive by research slide (table $3 \Downarrow$ ). The operational sensitivity of rapid diagnostic tests as used by chemical sellers was therefore $96 \%$ and specificity was $70 \%$ judged against the gold standard of double-read research slides. There was significant variation between chemical shops in terms of apparent specificity. Sensitivity and specificity of the rapid diagnostic test were calculated by shop, restricted to those shops that enrolled more than 100 clients. Sensitivity ranged from $98 \%$ to $100 \%$, suggesting that all shops were able to identify true cases. Most shops had specificity from $73 \%$ to $98 \%$, but two had a specificity of $30 \%$ and $31 \%$ and one of $52 \%$, despite the sellers having successfully completed training, raising the possibility that they were reporting positive rapid diagnostic tests to justify sales of antimalarials.

\section{Follow-up, referral, and safety}

There was no evidence that introducing rapid diagnostic tests led to major negative outcomes because true malaria cases were missed. Of 1179 clients with a positive slide reading, 1076 $(91.3 \%)$ were successfully followed up (670 intervention arm, 406 control) on day 28 after diagnosis, with missing data for five. Of these, $95.3 \%(1021 / 1071)$ completed the treatment they were sold by the chemical seller. There was no significant difference between the two study arms with regards to client completion of medication on follow-up $(\mathrm{P}=0.34)$. Five of them $(0.5 \%)$ did not receive any medicines from the chemical seller, while $4.2 \%$ (45/1071) admitted not completing their medications, of whom 34/45 did not because they felt better. Only four stopped taking their medications because of side effects.

Less than $1.5 \%$ (13/1071) of all the slide-positive clients followed up admitted to being referred to another health facility after their visit to the chemical seller, but significantly more of these were from the rapid diagnostic test arm $(\mathrm{P}=0.024)$. None of the clients who were followed up during the study period died. One adult female client died after the study ended; the death was not linked to the illness presented at the chemical shop nor the treatment given.

Of 1368 clients, 1088 (80\%) who tested negative with the rapid diagnostic test were referred to the formal healthcare sector, compared with only one client in the control arm. These were contacted by phone to find out whether the referral was completed. Of the 1088, 248 recalled being referred, 154 (62\%) reported that they went to the referral facility, while 94 (38\%) admitted to not going as they had been requested, and 54 said they did not go because they felt better.

Mystery client and 133 other chemical seller-client interaction observations in the intervention shops showed that chemical sellers adhered largely to safety instructions for handling sharps. For all 18 safety indicators assessed, the chemical sellers performed well. The range was between $87.2 \%$ and $100 \%$. The lowest indicator was the proportion of chemical sellers who discarded the lancet immediately into the sharps bin, which was $87.2 \%(116 / 133)$. Waste material from both bins was disposed of regularly in the incinerators of the nearest public sector health centre through a prior arrangement.

\section{Discussion}

Reducing overuse of antimalarials in the private sector is a public health priority. Most people with malaria or febrile symptoms, the commonest syndrome for severe illness in West Africa, are treated in the private drug retail sector, but the effect of introducing malaria diagnostics to this sector has been little studied. There has been considerable debate on whether to introduce rapid diagnostic tests into the private drug retail sector, but with limited current evidence of impact or safety. The incentives for drug shops (which want to sell drugs) are completely different than for clinicians, and turning shops into diagnostic centers for the most common acute condition (febrile illness) has significant policy implications. Despite this, pressure to introduce rapid diagnostic tests has been strong. For example, the Public Accounts Committee of the UK parliament recommended in 2013: "The [UK Government] should extend its support for rapid diagnostic tests to the private drug retail sector on a national or regional scale. to seize the unquestionable benefits this would bring." 40

This trial showed that introducing rapid diagnostic testing for malaria in chemical shops, the major private providers to poorer patients in Ghana, to guide dispensing practice of chemical sellers had a substantial impact on the dispensing of antimalarials. There was no change in prescribing artemisinin combination therapys to true malaria cases, but a significant reduction in dispensing antimalarials of all types, and artemisinin combination therapy specifically, was observed for malaria-negative cases. Although there was still some prescribing of antimalarials for test-negative clients, there was a substantial reduction in the number of potentially serious causes of infection which were being missed compared with standard care. A study carried out in two shops in Nigeria had similar findings. ${ }^{41}$ In the context of a country where antibiotics cannot be sold by shops, sales were diverted to antipyretics by the chemical sellers. No safety concerns were identified as a result of introducing rapid diagnostic tests after a short period of training, whether in not treating malaria cases, unexpected mortality, or sharps handling; this is an important issue in areas where hepatitis B is common and HIV prevalence is non-trivial. There was no evidence of reuse of lancets or improper disposal of sharps that could pose a danger to the public. There was an increase in appropriate referral of clients from the chemical shop to the formal healthcare sector.

Attempts to increase the proportion of children with fever who get antimalarials from the private drug retail sector such as the Affordable Medicines Facility for malaria have often been successful, but evidence of how to reduce overuse of antimalarials in those without malaria in the private sector has been lacking. ${ }^{42}$ Despite our not achieving the target sample size for the subgroup of children, the large effect estimates, small $\mathrm{P}$ 
values, and moderately narrow $95 \%$ confidence intervals provide evidence that an intervention effect exists and has been estimated with reasonable precision in this setting. There is now a wide body of literature on the effects of introducing rapid diagnostic tests in the formal health sector and community workers in Africa, albeit mainly from East Africa, and this has generally shown that introducing rapid diagnostic tests after a short period of training (like that provided here) is not sufficient to change behavior of healthcare workers. ${ }^{43}$ More prolonged training and ongoing supervision have generally been needed to achieve good results, probably because malaria treatment practices are driven by ingrained behaviours with multiple drivers ${ }^{44}$ in both providers and clients, ${ }^{46}$ but when undertaken is successful. ${ }^{47}$ Our study in Ghana demonstrates a more rapid change in behavior among shopkeepers when rapid diagnostic tests were first introduced than that found among health staff in the same setting. Health workers, particularly in a health facility where testing for malaria with microscopy was known, still prescribed antimalarials for a high proportion of test-negative patients. ${ }^{27}$ Clients visiting chemical shops in the intervention arm with complaints of fever were three times more likely to receive appropriate treatment for malaria fever than those visiting shops where no rapid diagnostic test testing was being done.

There is evidence from several settings that rapid diagnostic tests for malaria are not widely available in the private sector, but that in principle they are acceptable to clients and caregivers. ${ }^{48}{ }^{49}$ Although this study lends good support to the idea that rapid diagnostic tests can be introduced to the private drug retail sector and be both effective and safe, three caveats should be borne in mind. The first is the obvious one relevant to all trials; results found under trial conditions, even relatively operational trials such as this, are generally better than those found in subsequent operational practice. The second is that in this trial rapid diagnostic tests were introduced free. This establishes the principle that rapid diagnostic tests can be well used by shopkeepers if they are introduced without cost, such as by the Global Fund, but the financial incentives will change if the shopkeeper or client is paying for the test, and this could change behavior. How much rapid diagnostic tests are sold for is likely to influence uptake. ${ }^{50}$ The third is that chemical sellers are not supposed to prescribe most antibiotics in Ghana (although a few do), so one of the major risks of introducing rapid diagnostic tests in some other countries - that they lead to a switch from overuse of antimalarials to overuse of antibiotics where they are freely sold—was not tested here; sales were diverted almost exclusively to antipyretics or analgesics. Not using antibiotics seems to be safe in children with a negative rapid diagnostic test and without signs of severity; bacteremia rates are low in outpatient settings except in children $<1$ year old. ${ }^{51}$ Overprescription of antimalarials and the possible effects of rapid diagnostic tests in Ghana in the private drug retail sector is probably relevant to other settings. ${ }^{52}{ }^{53}$ There is the possibility that clients who are refused an antimalarial because of a negative rapid diagnostic test may go to another shop to get one, but follow-up data suggest this is rare (data not shown).

Anthropological data from other countries suggest patients want a diagnosis they trust, not a specific drug. ${ }^{54}$ There is the risk that shopkeepers changed their behaviour because blood samples for slides were being taken, but this was true in both trial arms and we think it unlikely that the large effect difference seen between arms is fully explained by this.

The major problem of overprescription of antimalarials to malaria-negative patients occurs in both the public and the private sector, but the private sector sees the majority of patients in Ghana. As the incidence of malaria drops in many settings, the importance of targeting of antimalarials to those who need them will increase. Considerable advances have been achieved in formal public sector settings by the use of rapid diagnostic tests. However, since most patients with fever and malaria are treated before they get to the formal sector, ensuring best targeting of antimalarials in the places such as shops where patients, and especially rural poorer patients, go, is essential. This study supports the idea that introduction of rapid diagnostic tests in the private drug retail sector with a realistic training package has the potential to be safe and effective.

We thank the chemical sellers in the Dangme West District and their clients for their participation in this trial, and the fieldworkers especially our field supervisors Michael Epokor and Samson Akanpigbiam. We also acknowledge the immense support provided by the Brian Greenwood, David Schellenberg, and the secretariat of the Malaria Capacity Development Consortium of the London School of Hygiene \& Tropical Medicine.

Contributors: EKA and CJMW designed the study, with input from SN-B and MG. EKA, SN-B, MG, HB, and CB-P performed the study with input from $B C$. EKA, BC, CJMW, and SN-B analyzed and interpreted the data. EKA, BC, and CJMW wrote the first draft of the manuscript. SN-B, $M G, H B$, and $C B-P$ contributed to the revision and finalization of the manuscript. All authors approved the final version of the manuscript. EKA is the study guarantor.

Funding: The study was sponsored by the Malaria Capacity Development Consortium of the London School of Hygiene \& Tropical Medicine with funding from the Welcome Trust and the Bill and Melinda Gates Foundation. The funders had no role in study design, data collection and analysis, decision to publish, or preparation of the manuscript.

Competing interests: All authors have completed the ICMJE uniform disclosure form at www.icmje.org/coi_disclosure.pdf and declare: no support from any organization for the submitted work; no financial relationships with any organizations that might have an interest in the submitted work in the previous three years; no other relationships or activities that could appear to have influenced the submitted work"

Ethical approval: The study received ethical approval from the Ethics Committee of the London School of Hygiene \& Tropical Medicine and the Ethical Review Committee of the Ghana Health Service.

Transparency declaration: The lead author (the manuscript's guarantor) affirms that the manuscript is an honest, accurate, and transparent account of the study being reported; that no important aspects of the study have been omitted; and that any discrepancies from the study as planned (and, if relevant, registered) have been explained.

1 Reyburn H, Mbatia R, Drakeley C, Carneiro I, Mwakasungula E, Mwerinde O, et al. Overdiagnosis of malaria in patients with severe febrile illness in Tanzania: a prospective study. BMJ 2004;329:1212.

2 Amexo M, Tolhurst R, Barnish G, Bates I. Malaria misdiagnosis: effects on the poor and vulnerable. Lancet 2004;364:1896-8.

3 World Health Organization. Malaria case management: operation manual. WHO, 2009:26. D'Acremont V, Lengeler C, Mshinda H, Mtasiwa D, Tanner M, Genton B. Time to move from presumptive malaria treatment to laboratory-confirmed diagnosis and treatment in African children with fever. PLOS Med 2009;6:e252.

5 English M, Esamai F, Wasunna A, Were F, Ogutu B, Wamae A, et al. Assessment of inpatient paediatric care in first referral level hospitals in 13 districts in Kenya. Lancet 2004;363:1948-53.

6 Van Dillen J, De Jager A, De Jong I, Wendte J. Overdiagnosis of malaria in hospitalized patients in Namibia. Tropical Doctor 2007:37:185-6.

7 Berkley J, Lowe B, Mwangi I, Williams T, Bauni E, Mwarumba S, et al. Bacteremia among children admitted to a rural hospital in Kenya. N Engl J Med 2005;352:39-47.

8 Snow R, Peshu N, Forster D, Mwenesi H, Marsh K. The role of shops in the treatment and prevention of childhood malaria on the coast of Kenya. Trans $R$ Soc Trop Med Hygiene 1992;86:237-9.

9 Mwenesi H, Harpham T, Snow RW. Child malaria treatment practices among mothers in Kenya. Soc Sci Med 1995;40:1271-7.

10 Nsimba SE, Warsame M, Tomson G, Massele AY, Mbatiya ZA. A household survey of source, availability, and use of antimalarials in a rural area of Tanzania. Drug Information J 1999;33:1025-32.

11 Rutebemberwa E, Pariyo G, Peterson S, Tomson G, Kallander K. Utilization of public or private health care providers by febrile children after user fee removal in Uganda. Malaria $J$ 2009;8:45. 


\section{What is already known on this topic}

Overdiagnosis of malaria is a major problem in Africa, and fever is the commonest potentially serious presentation

Most poorer patients in Africa are treated in the private drug retail sector, yet almost all evidence for improving diagnosis come exclusively from the public sector. However, the relationship between private sector seller and buyer is completely different from that between physician and patient, leading to different behaviours on both sides. Asking shopkeepers to not sell a drug in case of a negative test is potentially going against their self interest, and patients are generally coming to a shop for a product (rather than to a healthcare worker for a diagnosis), meaning their expectations are also different

\section{What this study adds}

This randomized trial provides rigorous evidence that rapid tests for malaria can substantially improve targeting of drugs safely in the private retail sector used by the poorest patients

Treatment in the chemical shop can be in good agreement with test results in the context of use of rapid diagnostic tests by chemical sellers

The results may not be generalizable to other settings such as urban areas and where drug retail shops are allowed to sell antibiotics, and the provision of free rapid diagnostic tests may not be possible outside schemes such as the Global Fund

12 Ahorlu CK, Dunyo SK, Afari EA, Koram KA, Nkrumah FK. Malaria-related beliefs and behaviour in Southern Ghana: Implications for treatment, prevention and control. Trop Med Int Health 1997;2:488-99.

13 Nonvignon J, Aikins MK, Chinbuah MA, Abbey M, Gyapong M, Garshong BN, et al. Research Treatment choices for fevers in children under-five years in a rural Ghanaian district. Malaria J 2010;9:188.

14 Asenso-Okyere W, Anum A, Osei-Akoto I, Adukonu A. Cost recovery in Ghana: are there any changes in health care seeking behaviour? Health Policy Plan 1998;13:181-8.

15 Hill Z, Kendall C, Arthur P, Kirkwood B, Adjei E. Recognizing childhood illnesses and their traditional explanations: exploring options for care-seeking interventions in the context of the IMCI strategy in rural Ghana. Trop Med Int Health 2003;8:668-76.

16 Littrell M, Gatakaa H, Evance I, Poyer S, Njogu J, Solomon T, et al. Monitoring fever treatment behaviour and equitable access to effective medicines in the context of initiatives to improve ACT access: baseline results and implications for programming in six African countries. Malaria J 2011;10:327.

17 Ensor T, Cooper S. Overcoming barriers to health service access: influencing the demand side. Health Policy Plan 2004;19:69-79.

18 Amooti-Kaguna B, Nuwaha F. Factors influencing choice of delivery sites in Rakai district of Uganda. Soc Sci Med 2000:50:203-13.

19 Rankin SL, Hughes-Anderson W, House AK, Heath DI, Aitken RJ, House J. Costs of accessing surgical specialists by rural and remote residents. ANZ J Surg 2001;71:544-7.

20 Rao VB, Schellenberg D, Ghani AC. Overcoming health systems barriers to successful malaria treatment. Trends Parasitol 2013;29:164-80.

21 Arrow KJ, Panosian CB, Gelband H. Saving lives, buying time: economics of malariia drugs in an age of resistance. Institute of Medicine, 2004.

22 Davis B, Ladner J, Sams K, Tekinturhan E, de Korte D, Saba J. Artemisinin-based combination therapy availability and use in the private sector of five AMFm phase countries. Malaria J 2013;12:135.

23 Malm KL, Segbaya S, Forson I, Gakpey KD, Sampong LB, Adjei EA, et al. Implementation of the Affordable Medicines for Malaria Facility (AMFm) in Ghana: processes, challenges and achievements. J Public Health Policy 2013;34:302-14.

24 D'Acremont V, Lengeler C, Genton B. Reduction in the proportion of fevers associated with Plasmodium falciparum parasitaemia in Africa: a systematic review. Malaria $J$ 2010:9:240.

25 Gething PW, Kirui VC, Alegana VA, Okiro EA, Noor AM, Snow RW. Estimating the number of paediatric fevers associated with malaria infection presenting to Africa's public health sector in 2007. PLoS Med 2010;7:e1000301.

26 Counihan H, Harvey SA, Sekeseke-Chinyama M, Hamainza B, Banda R, Malambo T, et al. Community health workers use malaria rapid diagnostic tests (RDTs) safely and accurately: results of a longitudinal study in Zambia. Am J Trop Med Hygiene 2012;87:57.

27 Ansah EK, Narh-Bana S, Epokor M, Akanpigbiam S, Quartey AA, Gyapong J, et al. Rapid testing for malaria in settings where microscopy is available and peripheral clinics where only presumptive treatment is available: a randomised controlled trial in Ghana. BMJ 2010;340:c930.

28 Masanja IM, Selemani M, Amuri B, Kajungu D, Khatib R, Kachur SP, et al. Increased use of malaria rapid diagnostic tests improves targeting of anti-malarial treatment in rural Tanzania: implications for nationwide rollout of malaria rapid diagnostic tests. Malaria $J$ 2012;11:221.

29 Agyepong I, Bruce E, Narh-Bana S, Ansah E, Gyapong M. Making health insurance and equitable and pro-poor financing mechanism in Ghana: some reflections. Med Educ Resources Africa (MERA), Ghana Edition 2006;21:5-14

30 Bastiaens GJ, Bousema T, Leslie T. Scale-up of malaria rapid diagnostic tests and artemisinin-based combination therapy: challenges and perspectives in sub-Saharan Africa. PLoS Med 2014;11:e1001590.

31 Abba K, Deeks JJ, Olliaro P, Naing CM, Jackson SM, Takwoingi Y, et al. Rapid diagnostic tests for diagnosing uncomplicated $\mathrm{P}$. falciparum malaria in endemic countries. Cochrane Database Syst Rev 2011;(7):CD008122.

32 Yeung $\mathrm{S}$, Patouillard $\mathrm{E}$, Allen $\mathrm{H}$, Socheat $\mathrm{D}$. Socially-marketed rapid diagnostic tests and ACT in the private sector: ten years of experience in Cambodia. Malaria J 2011;10:243.

33 Nkrumah B, Owusu M, Averu P. Hepatitis B and C viral infections among blood donors. A retrospective study from a rural community of Ghana. BMC Res Notes 2011;4:529.

34 Fritzsche C, Becker F, Hemmer C, Riebold D, Klammt S, Hufert F, et al. Hepatitis B and $\mathrm{C}$ : neglected diseases among health care workers in Cameroon. Trans $R$ Soc Trop Med Hygiene 2013;107:158-64.

35 Agyepong IA. Malaria: ethnomedical perceptions and practice in an Adangbe farming community and implications for control. Soc Sci Med 1992;35:131-7.

36 Agyepong IA, Manderson L. The diagnosis and management of fever at household leve in the Greater Accra Region, Ghana. Acta Tropica 1994:58:317-30.

37 Raab GM, Butcher I. Balance in cluster randomized trials. Stat Med 2001:20:351-65.

38 Moulton LH. Covariate-based constrained randomization of group-randomized trials. Clin Trials 2004;1:297-305.

39 Hayes RJ, Moulton LH. Cluster randomised trials. CRC Press London, 2009.
40 Ansah EK, Epokor M, Whitty CJ, Yeung S, Hansen KS. Cost-effectiveness analysis of introducing RDTs for malaria diagnosis as compared to microscopy and presumptive diagnosis in central and peripheral public health facilities in Ghana. Am J Trop Med Hygiene 2013;89:724-36.

41 Ansah EK, Powell-Jackson T. Can we trust measures of healthcare utilization from household surveys? BMC Public Health 2013;13:853.

42 Kangwana BP, Kedenge SV, Noor AM, Alegana VA, Nyandigisi AJ, Pandit J, et al. The impact of retail-sector delivery of artemether-lumefantrine on malaria treatment of children under five in Kenya: a cluster randomized controlled trial. PLOS Med 2011:8:e1000437.

43 Reyburn H, Mbakilwa H, Mwangi R, Mwerinde O, Olomi R, Drakeley C, et al. Rapid diagnostic tests compared with malaria microscopy for guiding outpatient treatment of febrile illness in Tanzania: randomised trial. BMJ 2007;334:403.

44 Mubi M, Janson A, Warsame M, Mårtensson A, Källander K, Petzold MG, et al. Malaria rapid testing by community health workers is effective and safe for targeting malaria treatment: randomised cross-over trial in Tanzania. PloS One 2011;6:e19753.

45 Chandler C, Jones C, Boniface G, Juma K, Reyburn H, Whitty C. Guidelines and mindlines: why do clinical staff over-diagnose malaria in Tanzania? A qualitative study. Malaria $\mathrm{J}$ 2008;7:53.

46 Ansah EK, Reynolds J, Akanpigbiam S, Whitty CJ, Chandler Cl. "Even if the test result is negative, they should be able to tell us what is wrong with us": a qualitative study of patient expectations of rapid diagnostic tests for malaria. Malaria $J$ 2013:12:1-10.

47 Yukich JO, Bennett A, Albertini A, Incardona S, Moonga H, Chisha Z, et al. Reductions in artemisinin-based combination therapy consumption after the nationwide scale up of routine malaria rapid diagnostic testing in Zambia. Am J Trop Med Hygiene 2012;87:437.

48 Albertini A, Djalle D, Faye B, Gamboa D, Luchavez J, Mationg M, et al. Preliminary enquiry into the availability, price and quality of malaria rapid diagnostic tests in the private health sector of six malaria-endemic countries. Trop Med Int Health 2012;17:147-52.

49 Baiden F, Owusu-Agyei S, Okyere E, Tivura M, Adjei G, Chandramohan D, et al. Acceptability of rapid diagnostic test-based management of malaria among caregivers of under-five children in rural Ghana. PloS One 2012;7:e45556.

50 Hansen KS, Pedrazzoli D, Mbonye A, Clarke S, Cundill B, Magnussen P, et al. Willingness-to-pay for a rapid malaria diagnostic test and artemisinin-based combination therapy from private drug shops in Mukono district, Uganda. Health Policy Plan 2013:28:185-96.

51 Mtove G, Hendriksen I, Amos B, Mrema H, Mandia V, Manjurano A, et al. Treatment guided by rapid diagnostic tests for malaria in Tanzanian children: safety and alternative bacterial diagnoses. Malaria J 2011;10:290.

52 Mbonye AK, Lal S, Cundill B, Hansen KS, Clarke S, Magnussen P. Treatment of fevers prior to introducing rapid diagnostic tests for malaria in registered drug shops in Uganda. Malaria J 2013;12:131.

53 Cohen J, Fink G, Berg K, Aber F, Jordan M, Maloney K, et al. Feasibility of distributing rapid diagnostic tests for malaria in the retail sector: evidence from an implementation study in Uganda. PloS One 2012;7:e48296.

54 Chandler $\mathrm{Cl}$, Mwangi R, Mbakilwa H, Olomi R, Whitty CJ, Reyburn H. Malaria overdiagnosis: is patient pressure the problem? Health Policy Plan 2008;23:170-8.

Accepted: 26 January 2015

Cite this as: BMJ 2015;350:h1019

\section{Related links}

\section{thebmj.com}

- Research: Investigation and treatment of imported malaria in non-endemic countries (BMJ 2013; 346: f2900)

- Research: Overdiagnosis and mistreatment of malaria among febrile patients at primary healthcare level in Afghanistan (BMJ 2012; 345: e4389)

- Research: Risk factors for mortality from imported falciparum malaria in the United Kingdom over 20 years (BMJ 2012; 344: e2116) 
- Research: Protective efficacy of co-trimoxazole prophylaxis against malaria in HIV exposed children in rural Uganda (BMJ 2011;342:d1617)
This is an Open Access article distributed in accordance with the Creative Commons Attribution Non Commercial (CC BY-NC 4.0) license, which permits others to distribute, remix, adapt, build upon this work non-commercially, and license their derivative works on different terms, provided the original work is properly cited and the use is non-commercial. See: http://creativecommons.org/licenses/by-nc/4.0/. 


\section{Tables}

\begin{tabular}{|c|c|c|}
\hline & RDT arm & Control arm \\
\hline Cluster level & $(n=12)$ & $(n=11)$ \\
\hline Median (range) No of shops per cluster & $2(1-5)$ & $2(1-5)$ \\
\hline Median (range) No of clients per cluster & $214(17-572)$ & $213(51-231)$ \\
\hline \multicolumn{3}{|l|}{ Location: } \\
\hline Urban only & 0 & 0 \\
\hline Rural only & $1(8)$ & $3(27)$ \\
\hline Both & $11(92)$ & $8(73)$ \\
\hline Shop level & $(n=27)$ & $(n=24)$ \\
\hline \multicolumn{3}{|l|}{ No of sellers per shop: } \\
\hline $1-3$ & $26(96)$ & $23(96)$ \\
\hline $4-6$ & $1(4)$ & $1(4)$ \\
\hline \multicolumn{3}{|l|}{ Regular seller: } \\
\hline Owner & $12(44)$ & $14(58)$ \\
\hline Employee/assistant & $14(52)$ & $10(42)$ \\
\hline Family & $1(4)$ & $0(0)$ \\
\hline \multicolumn{3}{|l|}{ Education level of respondent: } \\
\hline Primary & $1(4)$ & $0(0)$ \\
\hline Secondary & $20(74)$ & $18(75)$ \\
\hline Tertiary & $6(22)$ & $6(25)$ \\
\hline \multicolumn{3}{|l|}{ Formal training in medicine dispensing*: } \\
\hline No & $11(41)$ & $6(25)$ \\
\hline Yes & $16(59)$ & $18(75)$ \\
\hline \multicolumn{3}{|l|}{ Refresher training in past 6 months $^{*}$ : } \\
\hline No & $15(56)$ & $6(25)$ \\
\hline Yes & $12(44)$ & $18(75)$ \\
\hline \multicolumn{3}{|l|}{ Reported average No of clients per day: } \\
\hline$<20$ & $6(22)$ & $8(33)$ \\
\hline $21-30$ & $7(26)$ & $5(21)$ \\
\hline$\geq 30$ & $14(52)$ & $11(46)$ \\
\hline Client level & $(n=2719)$ & $(n=2029)$ \\
\hline Median (IQR) age (years) & $15(6-29)$ & $19(6-32)$ \\
\hline \multicolumn{3}{|l|}{ Age group: } \\
\hline$<5$ years & $534(20)$ & $390(19)$ \\
\hline 5-12 years & $719(26)$ & $458(23)$ \\
\hline$\geq 13$ years & $1466(54)$ & $1181(58)$ \\
\hline \multicolumn{3}{|l|}{ Sex: } \\
\hline Male & $1343(49)$ & $997(49)$ \\
\hline Female & $1376(51)$ & $1032(51)$ \\
\hline \multicolumn{3}{|l|}{ Community of residence: } \\
\hline Urban & $1198(44)$ & $730(36)$ \\
\hline Rural & $1521(56)$ & $1299(64)$ \\
\hline
\end{tabular}

RDT=Rapid diagnostic test for malaria.

${ }^{*}$ Formal training refers to a 1 year training in medicine dispensing. Refresher training refers to training lasting from half a day to a maximum of three days usually organized by the Pharmacy Council (the regulatory body), pharmaceutical companies, or other health agencies in specific subject areas. 


\begin{tabular}{|c|c|c|c|c|c|c|c|c|c|}
\hline & \multicolumn{2}{|c|}{ Control (no RDT) arm } & \multicolumn{2}{|c|}{ Intervention (RDT) arm } & \multicolumn{2}{|c|}{ Crude results* } & \multicolumn{2}{|c|}{ Adjusted results† } & \multirow[b]{2}{*}{$\begin{array}{c}k \\
\text { statistic }\end{array}$} \\
\hline & $\begin{array}{l}\text { No of } \\
\text { clusters }\end{array}$ & $\begin{array}{l}\text { Prevalence } \\
\text { (\%) among } \\
\text { clients }\end{array}$ & $\begin{array}{l}\text { No of } \\
\text { clusters }\end{array}$ & $\begin{array}{l}\text { Prevalence } \\
\text { (\%) among } \\
\text { clients }\end{array}$ & $\begin{array}{l}\text { Risk ratio } \\
(95 \% \mathrm{Cl})\end{array}$ & $P$ value & $\begin{array}{l}\text { Risk ratio } \\
(95 \% \mathrm{Cl})\end{array}$ & $P$ value & \\
\hline \multicolumn{10}{|c|}{ Primary outcome: slide result negative, client receives antimalarialł } \\
\hline All clients & 11 & $\begin{array}{c}1378 / 1570 \\
(88)\end{array}$ & 12 & $590 / 1854(32)$ & $\begin{array}{c}0.34(0.26 \text { to } \\
0.44)\end{array}$ & $<0.0001$ & $\begin{array}{c}0.41(0.29 \text { to } \\
0.58)\end{array}$ & $<0.0001$ & 0.52 \\
\hline Adults & 11 & $853 / 1013(84)$ & 12 & $334 / 1179(28)$ & $\begin{array}{c}0.33(0.25 \text { to } \\
0.43)\end{array}$ & $<0.0001$ & $\begin{array}{c}0.40(0.28 \text { to } \\
0.56)\end{array}$ & $<0.0001$ & 0.55 \\
\hline Children & 11 & $525 / 557(94)$ & 12 & $256 / 675(38)$ & $\begin{array}{c}0.40(0.29 \text { to } \\
0.56)\end{array}$ & $<0.0001$ & $\begin{array}{c}0.52(0.36 \text { to } \\
0.74)\end{array}$ & 0.006 & 0.45 \\
\hline \multicolumn{10}{|c|}{ Secondary outcomes } \\
\hline $\begin{array}{l}\text { Appropriate } \\
\text { treatment§ }\end{array}$ & 11 & $539 / 1962(27)$ & 12 & $\begin{array}{c}1954 / 2641 \\
(74) \\
\end{array}$ & $\begin{array}{c}2.86(2.24 \text { to } \\
3.63)\end{array}$ & $<0.0001$ & $\begin{array}{c}2.39(1.69 \text { to } \\
3.39)\end{array}$ & $<0.0001$ & - \\
\hline $\begin{array}{l}\text { ACT to } \\
\text { slide-positive } \\
\text { client } \emptyset\end{array}$ & 11 & $347 / 392(89)$ & 12 & $690 / 787$ (88) & $\begin{array}{c}0.94(0.81 \text { to } \\
1.09)\end{array}$ & 0.42 & $\begin{array}{c}0.96(0.84 \text { to } \\
1.09)\end{array}$ & 0.47 & - \\
\hline $\begin{array}{l}\text { No } \\
\text { antimalarial to } \\
\text { slide-negative } \\
\text { client }\end{array}$ & 11 & $192 / 1570(12)$ & 12 & $\begin{array}{c}1264 / 1854 \\
(68)\end{array}$ & $\begin{array}{c}5.94(3.32 \text { to } \\
10.65)\end{array}$ & $<0.0001$ & $\begin{array}{c}5.28(2.59 \text { to } \\
10.77)\end{array}$ & $<0.0001$ & - \\
\hline $\begin{array}{l}\text { Antibiotic to } \\
\text { slide-negative } \\
\text { client }\end{array}$ & 11 & $1 / 1570(0.1)$ & 12 & $6 / 1854(0.3)$ & - & - & - & - & - \\
\hline $\begin{array}{l}\text { Analgesic or } \\
\text { antipyretic to } \\
\text { slide-negative } \\
\text { client }\end{array}$ & 11 & $108 / 1570(7)$ & 12 & 629/1854 (34) & $\begin{array}{c}4.29(2.09 \text { to } \\
8.84)\end{array}$ & 0.004 & $\begin{array}{c}3.46(1.64 \text { to } \\
7.32)\end{array}$ & 0.013 & - \\
\hline
\end{tabular}

RDT=rapid diagnostic test for malaria. $A C T=$ artemisinin combination therapy

*Adjusted for clustering, based on geometric mean of cluster summaries.

†Adjusted for clustering, age, sex, number of clients per cluster, number of shops per cluster, and characteristics of sellers (including whether they were the regular seller and had formal training or refresher training in the previous six months).

‡Receiving an ACT or other antimalarial. Restricting the outcome to ACT only provides similar results; 1285 (82\%) in the control arm; 557 (30\%) in the RDT arm; adjusted risk ratio 0.37 (95\% $\mathrm{Cl} 0.28$ to 0.51$), \mathrm{P}<0.0001$.

$\S$ Appropriate treatment defined as slide-positive client receiving an ACT or slide-negative client not receiving an antimalarial.

IAmong the 45 slide-positive clients in the control arm not receiving an ACT, 22 (49\%) received other antimalarial, 8 (18\%) received analgesic, 5 (11\%) received no medicines, and $10(22 \%)$ received other medicines. In the RDT arm, 70/97 (72\%) slide-positive clients not receiving an ACT received other antimalarial, 15 $(15 \%)$ received analgesic, and $12(12 \%)$ received no medicines. 
Table 3/ Comparative results of the rapid diagnostic test (RDT) as used by chemical sellers and research blood slide results

\begin{tabular}{lccc} 
& \multicolumn{3}{c}{ RDT results } \\
\cline { 2 - 4 } Slide results & Positive & Negative & Total \\
Positive & 758 & 29 (false negative) & 787 \\
\hline Negative & 559 (false positive) & 1295 & 1854 \\
\hline Inadequate sample & 34 & 44 & 78 \\
\hline Total & 1351 & 1368 & 2719 \\
\hline
\end{tabular}




\section{Figures}

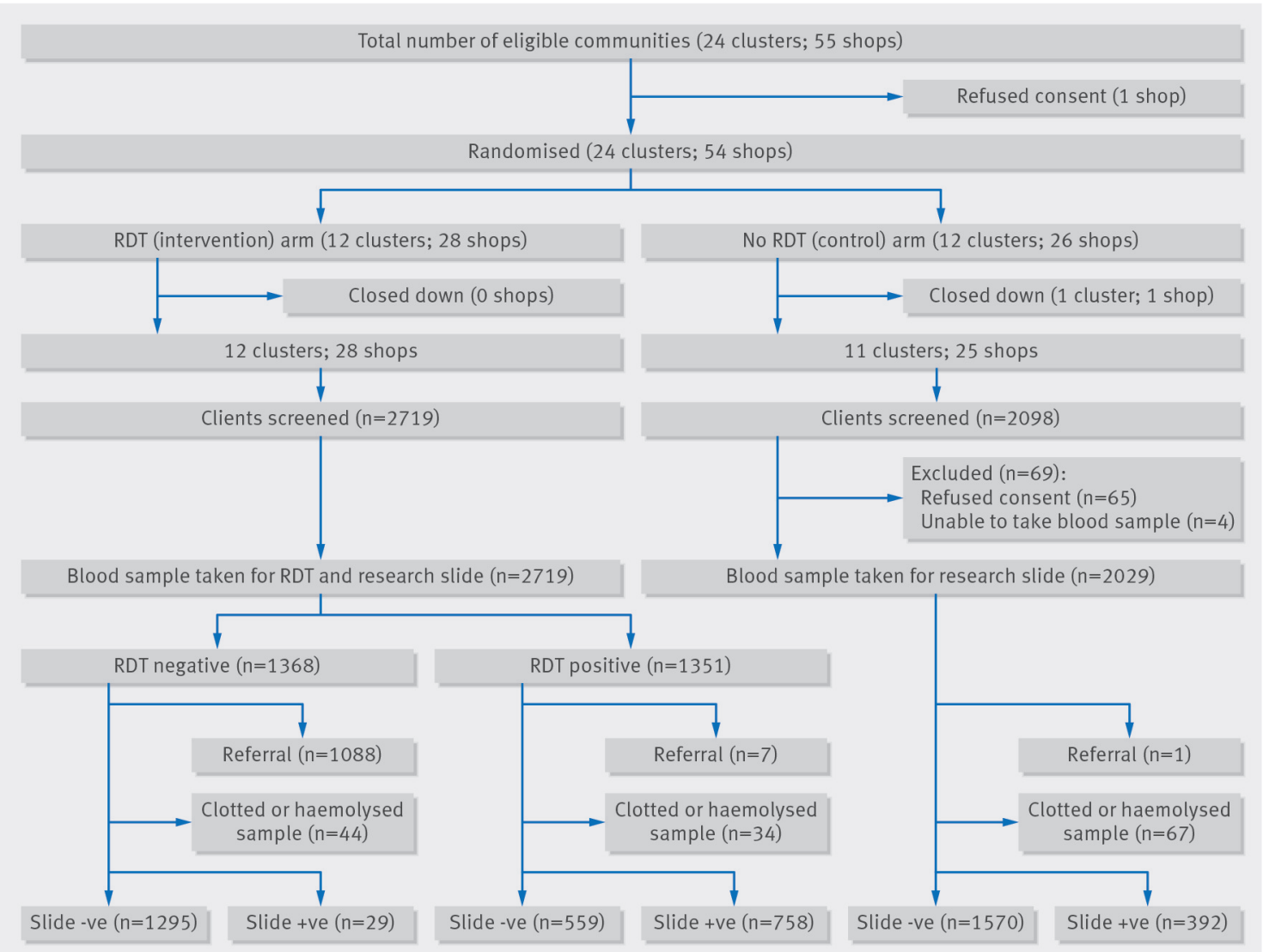

Fig 1 Trial profile: rapid diagnostic test versus normal practice in Licensed Chemical shops

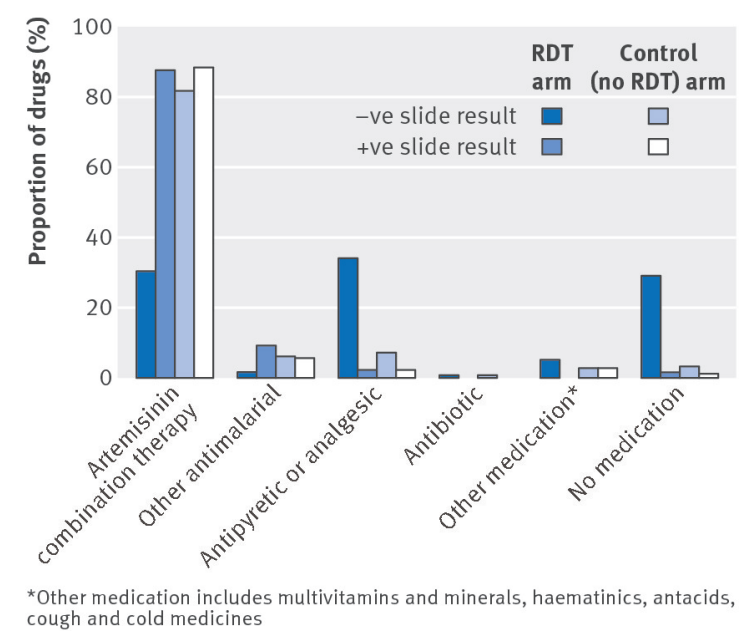

Fig 2 Medicines dispensed by chemical sellers with or without a rapid diagnostic test (RDT) for malaria, by the subsequent blood slide results (not available to chemical seller to guide dispensing) 


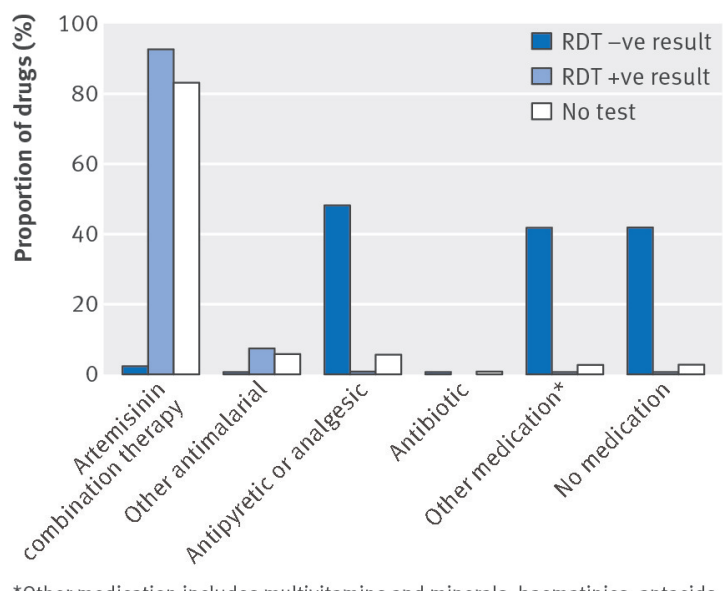

* Other medication includes
cough and cold medicines

Fig 3 Medicines dispensed by chemical sellers based on rapid diagnostic test (RDT) for malaria 